\title{
TITLE:
}

\section{Delocalization boosts charge separation in organic solar cells}

\author{
$\operatorname{AUTHOR}(\mathrm{S}):$ \\ Tamai, Yasunari
}

CITATION:

Tamai, Yasunari. Delocalization boosts charge separation in organic solar cells. Polymer Journal 2020, 52:691-700

ISSUE DATE:

2020-07

URL:

http://hdl.handle.net/2433/254204

\section{RIGHT:}

This is the accepted manuscript of the article, which has been published in final form at https://doi.org/10.1038/s41428020-0339-4. The full-text file will be made open to the public on 16 October 2020 in accordance with publisher's 'Terms and Conditions for Self-Archiving'.; この論文は出版社版でありません。引用の際には出版社版をご確認ご利用ください ॰ ; This is not the published version. Please cite only the published version. 


\section{Delocalisation boosts charge separation in organic solar cells}

\section{Author:}

Yasunari Tamai ${ }^{1,2 *}$

${ }^{1}$ Department of Polymer Chemistry, Graduate School of Engineering, Kyoto University,

Katsura, Nishikyo, Kyoto 615-8510, Japan

${ }^{2}$ Japan Science and Technology Agency (JST), PRESTO, 4-1-8 Honcho Kawaguchi,

Saitama 332-0012, Japan

\section{Corresponding Author:}

YT: tamai@photo.polym.kyoto-u.ac.jp

Running Head: Delocalisation boosts charge separation in OSCs

\section{Keywords:}

bulk heterojunction, charge dissociation, charge transfer, exciton dissociation, organic photovoltaics, polymer solar cells, transient absorption 


\section{Abstract}

Organic solar cells (OSCs) utilising $\pi$-conjugated polymers have attracted widespread interest over the past three decades because of their potential advantages, including light weight, thin film flexibility, and low-cost manufacturing. However, their power conversion efficiency (PCE) has been far below that of inorganic analogues. Geminate recombination of charge transfer excitons is a major loss process in OSCs. This paper reviews our recent progress in using transient absorption spectroscopy to understand geminate recombination in bulk heterojunction OSCs, including the impact of polymer crystallinity on charge generation, and charge dissociation mechanisms in nonfullerene acceptor-based OSCs. The first example of high PCE with small photon energy loss is also given. The importance of delocalisation of the charge wave function to suppress geminate recombination is highlighted by this focus review.

\section{Introduction}

Over the past three decades, organic solar cells (OSCs) utilising $\pi$-conjugated polymers have attracted widespread interest because of their potential advantages, including light weight, thin film flexibility, and low-cost manufacturing [1-4]. When a light is shined on semiconducting polymers, singlet excitons, i.e. Coulombically bound electron-hole (e- 
h) pairs instead of free charge carriers, are promptly generated because of their small dielectric constants. This is in sharp contrast to inorganic semiconductors such as silicon, in which light absorption directly results in the generation of free electrons and holes in the conduction and valence bands, respectively. OSCs require a donor-acceptor (DA) heterojunction to ionize singlet excitons, where, as a result of the offset in the lowest unoccupied molecular orbital (LUMO) or highest occupied molecular orbital (HOMO) energy at the DA interface, singlet excitons separate into holes on the donor and electrons on the acceptor. If the electron and hole separate further, they become free from Coulombic attraction, and hence survive up to nano- or microseconds, long enough to be transported to each electrode. Otherwise, the geminate e-h pairs are likely to recombine to the ground state (Figure 1).

$<<<$ Figure $1>>>$

Historically, geminate recombination has been one of the most detrimental processes for OSCs. Singlet excitons in blends of regiorandom poly(3-hexylthiophene) (RRa-P3HT) and a fullerene derivative PCBM undergo efficient charge transfer (CT) at the DA interface (the quantum efficiency of CT at the DA interface is nearly unity); however, CT 
excitons then experience strong geminate recombination within $\sim 2$ ns ( $\sim 70 \%$ of CT excitons geminately decay to the ground state) [5]. Higher performing OSCs have generally consisted of crystalline donor polymers such as regioregular P3HT (RR-P3HT) blended with either PCBM or its C70 analogue $\mathrm{PC}_{71} \mathrm{BM}$. For example, in blends of RRP3HT and PCBM, >90\% of CT excitons dissociate into free charge carriers [5]. Therefore, it is important to understand how polymer crystallisation impacts charge dissociation efficiency.

Nonfullerene acceptors (NFAs) have been considered as an alternative to fullerenes. They provide stronger optical absorption in the visible to near-IR region, allowing easier optimisation of the molecular orbital energy. Until recently, however, NFA-based OSCs routinely lagged in charge generation efficiency, and hence power conversion efficiency (PCE), behind their fullerene-based analogues [6-8]. One reason for the lower device efficiency of NFA-based OSCs is that most NFA-based OSCs suffer from terrible geminate recombination loss [9-14]. For example, blends of PBDTTT-C and a perylene diimide (PDI) monomer lost more than half of the CT excitons through geminate recombination on the sub-nanosecond time scale [14]. As a result, fullerenes were considered "special” electron acceptors for a long time. Thanks to development of new NFAs, the PCEs for NFA-based OSCs have improved very rapidly $[4,15,16]$, and 
currently some NFA-based OSCs have a far superior PCE to conventional fullerene-based OSCs [17-19]. In contrast to the rapid improvement of device efficiency, the fundamental mechanisms for charge generation and recombination in NFA-based OSCs are still being debated. It is important to understand whether the models developed for fullerene acceptor systems are also applicable to efficient NFA systems.

Another remaining challenge in this field is to reduce photon energy loss ( $\left.E_{\text {loss }}\right)$ in OSCs, which is defined as the difference between the optical bandgap $\left(E_{\mathrm{g}}\right)$ of the materials and the open-circuit voltage ( $\left.V_{\mathrm{OC}}\right)\left(E_{\text {loss }}=E_{\mathrm{g}}-q V_{\mathrm{OC}}\right.$ where $q$ is an elementary charge). It is well known that the $E_{\text {loss }}$ in OSCs is typically more than $0.7 \mathrm{eV}$ [20], which is much larger than that in the silicon-based solar cell ( $E_{\text {loss }}$ is only $\sim 0.4 \mathrm{eV}$ ). This is partly because OSCs require a DA heterojunction to ionize the excitons as mentioned above, resulting in a reduction of energy from $E_{\mathrm{g}}$ to the CT state energy $E_{\mathrm{CT}}$. Historically, it has been considered that a LUMO (or HOMO) energy offset of more than $0.3 \mathrm{eV}$ is necessary for efficient charge generation. For example, Li et al. found a strong correlation between the LUMO energy offset and the external quantum efficiency (EQE) [21]. The energy offset was varied by using various donor polymers with fullerene acceptors, and it was found that the EQE drops sharply when the $E_{\text {loss }}$ is less than $0.6 \mathrm{eV}$. This is rationalised by an insufficient driving force for charge generation as a result of the small LUMO energy 
offset. OSCs that exhibit efficient charge generation despite a small energy offset are therefore strongly required.

We have tackled above mentioned challenges by using transient absorption (TA) spectroscopy. TA spectroscopy is one of the most powerful and useful tools for tracking the time evolution of transient species in OSCs, such as excitons and charges, with high temporal resolution [22-31]. In this focus review, our recent findings regarding the dissociation of CT excitons into free charge carriers are summarised. The impacts of polymer crystallisation on charge dissociation efficiency [24] and mechanisms of charge dissociation in an efficient NFA-based OSCs [31] are discussed. Finally, an example of efficient charge generation with small LUMO energy offset is introduced [28].

\section{Impacts of polymer crystallisation on charge dissociation efficiency}

Many previous studies have pointed out that crystallisation or aggregation of materials promotes charge dissociation in OSCs [5,32-37]. However, exactly how polymer crystallinity impacts charge dissociation is still unclear. Herein, we discuss the impact of polymer crystallisation on charge dissociation in blends of various donor polymers with PCBM [24]. Figure 2a shows the TA spectra of a PSBTBT/PCBM blend film as an example. A positive signal around $1500 \mathrm{~nm}$ observed immediately after photoexcitation 
is attributable to a photoinduced absorption (PIA) band of PSBTBT singlet excitons. Even just after the photoexcitation ( $t=0 \mathrm{ps}$ ), the TA amplitude of the singlet exciton band is reduced compared with that of the PSBTBT pristine film, indicating that some excitons dissociate to charge pairs within the time resolution of our TA system ( 130 fs, full width at half maximum). Instead, another PIA band ascribable to polymer hole polarons was observed, ranging from 800 to $1300 \mathrm{~nm}$ for the blend film. Note that the PCBM anion has a PIA band centred at $1020 \mathrm{~nm}$ [5], but this band was not observed because of its small absorption cross-section. The singlet excitons decayed with a time constant of $0.8 \mathrm{ps}$, and the polaron band became more pronounced at the same time. At 10 ps after photoexcitation, singlet excitons completely disappeared, and a broad polaron band with peaks at 1000 and $1300 \mathrm{~nm}$ was clearly observed. Interestingly, decay kinetics monitored at $1000 \mathrm{~nm}$ were faster than those monitored at $1300 \mathrm{~nm}$, indicating that there are at least two distinct charged states in the PSBTBT domains. We found that the band at $1000 \mathrm{~nm}$ could be assigned to polarons generated in the PSBTBT disordered phase, and the band at $1300 \mathrm{~nm}$ to the PSBTBT crystalline phase. Figure $2 \mathrm{~b}$ shows the decay kinetics of those two polarons after $10 \mathrm{ps}$. Interestingly, the population of polarons in the crystalline phase still increased with a time constant of $~ 24$ ps, even though singlet excitons had completely disappeared at this point. We found that the increase of polarons in the crystalline phase 
was accompanied by a decrease of polarons in the disordered phase, indicating that some of the polarons in the disordered phase were transferred to the crystalline phase. Within a nanosecond time scale, about a half the polarons in the disordered phase decayed geminately, whilst geminate recombination was negligible in the crystalline phase.

$<<<$ Figure $2>>>$

Charge dissociation efficiencies for other blends are summarised in Table 1 [5,37-44].

We first focus on the impacts of hole transfer from the disorder phase to the crystalline phase observed in PSBTBT/PCBM blends. A similar hole transfer has been reported for RR-P3HT/PCBM blends [5]. Owing to the hole transfer from the disordered phase to the crystalline phase, charge dissociation efficiency in the disordered phase $\left(\eta_{\mathrm{CD}}{ }^{\mathrm{dis}}\right)$ in blends of crystalline donor polymers is higher than that in amorphous RRa-P3HT blends. The driving force for the hole transfer is believed to be potential energy cascades between the crystalline and interfacial disordered phases. Previous studies have established that most OSCs consist of nanoscale domains of pure polymers, pure fullerenes, and the intermixed regions in between [45-48]. Thus, the three-phase morphology introduced by polymer crystallisation would be a key driver for efficient charge dissociation through the hole 
transfer [34] because the ionization potential of conjugated polymers, in general, is reduced with increasing polymer crystallinity, resulting in a HOMO energy cascade between the intermixed disordered phase and the pure polymer crystalline phase [49].

$<<<$ Table $1>>>$

The charge dissociation efficiency is clearly dependent on the blend morphology. Quantum efficiencies of charge dissociation in crystalline phases ( $\left.\eta_{\mathrm{CD}}{ }^{\text {cry }}\right)$ are nearly unity, which is surprisingly high according to the conventional charge dissociation model based on the Braun-Onsager framework [1]. According to the Braun-Onsager framework, an electron and a hole are tightly bound at the DA interface by strong Coulombic attraction because the dielectric constants of organic materials are low, and hence efficient charge dissociation requires a strong electric field $\left(>10^{8} \mathrm{~V} \mathrm{~m}\right)$ and/or a high temperature. However, this is not true for most OSCs, wherein electric field and temperature independent charge dissociation has been observed [32,50]. We found a positive correlation between dissociation efficiency and crystalline coherent length in the $\pi$ stacking direction $L_{010}$, suggesting that delocalisation of hole polarons in the crystalline phase plays a key role in the charge dissociation. As shown in Table 1, high charge 
dissociation efficiencies are observed for crystalline polymers with a correlation length of $L_{010}>4 \mathrm{~nm}$, which is comparable to the effective Coulombic capture radius at the DA interface, taking into account the entropic contribution to the Gibbs free energy [1]. We therefore conclude that large delocalisation of hole wave functions in polymer crystalline phases promotes charge dissociation. Our findings would be consistent with spectroscopic studies reported by Friend and co-workers, wherein ultrafast long-range charge separation occurs through access to band-like electron states in fullerene aggregates [35].

\section{Ultrafast charge dissociation in nonfullerene acceptor-based solar cells}

The charge dissociation mechanisms in NFA-based OSCs are exemplified in blends of a benchmark donor polymer, PTB7-Th, and an efficient NFA, bay-di-PDI [31]. Figure 3a shows the femtosecond TA spectra for the PTB7-Th/bay-di-PDI blend under the selective excitation of PTB7-Th. The large positive band in the visible region is ascribed to groundstate bleaching (GSB), and a broad PIA tail observed around $1400 \mathrm{~nm}$ is attributable to polymer singlet excitons. Singlet excitons rapidly decayed with a lifetime of 1.3 ps. Because the intrinsic exciton lifetime of PTB7-Th is 220 ps, this indicates that almost all excitons were converted into charged species. The PIA centred at $1150 \mathrm{~nm}$ became 
dominant within 10 ps, which can be ascribed to hole polarons on the donor polymer. Note that PIA band of bay-di-PDI radical anion was not observed because it fully overlaps with the large GSB band [51]. Hole polarons, then, remained almost unchanged until the nanosecond time scale. For comparison, Figure 3b shows the TA spectra for the PTB7$\mathrm{Th} / \mathrm{PC}_{71} \mathrm{BM}$ blend film. As in the PDI blend, the polaron band remain unchanged until 1 ns. Note that an additional PIA band was observed at $1300 \mathrm{~nm}$ at later times only for the $\mathrm{PC}_{71} \mathrm{BM}$ blend, which we attribute to polymer triplet absorption formed through bimolecular charge recombination [52-54].

$<<<$ Figure 3 $>>>$

Figure 4a,b shows the normalised TA spectra in the visible region. We found that both the peak position and onset of the main GSB band blue-shift even after singlet excitons have been fully quenched. This indicates that a small PIA overlaps this region, with dynamics different to both singlet excitons and charges. In line with previous results [35], we attribute this to the electroabsorption (EA) of PTB7-Th. When an exciton dissociates into an e-h pair, a dipole-like local electric field is generated in its surroundings. This results in a Stark shift for surrounding molecules, adding a first-derivative-like spectrum 
component to the TA data. As the amplitude of the EA signal is a function of the local electric field, i.e. a function of separation distance of the e-h pair, we can directly quantify the separation distance of the $\mathrm{e}-\mathrm{h}$ pair. Figure $4 \mathrm{c}$ shows the time evolution of the EA amplitude. For the $\mathrm{PC}_{71} \mathrm{BM}$ blend, the EA amplitude is already large at $200 \mathrm{fs}$, and reaches its maximum by $400-500$ fs. As shown in the right axis of Figure 4c, the EA amplitude was converted into electrostatic energy stored in the field per an e-h pair, which was calculated as $\frac{1}{2} \varepsilon_{0} \varepsilon_{\mathrm{r}} \int|E|^{2} d V$ and calibrated against quasi steady-state EA measurements on diode structures. During this short duration, electrostatic energy of $200 \mathrm{meV}$ was stored in the field, which is well above the thermal energy at room temperature and on the same order of the CT state binding energy. This indicates that the e-h pair undergoes rapid spatial separation, despite the opposing Coulombic attraction. This picture is again inconsistent with the Braun-Onsager framework, but is consistent with ballistic charge separation through delocalised wave function [35]. Interestingly, the EA amplitude of the PDI blend is as large as that of the $\mathrm{PC}_{71} \mathrm{BM}$ blend, indicating that charge separation mechanisms for the PDI blend can be rationalised by the ballistic charge separation model. Before our study, ballistic charge separation was only observed in blends that consist of relatively large fullerene aggregates. However, we provided clear experimental evidence that ballistic charge separation can also take place in NFA-based blends, and hence the 
model that charges separate coherently through delocalised states can be more widely applied to various types of OSCs.

$<<<$ Figure $4>>>$

Figure 5a shows the time evolution of polaron signals in the PDI and $\mathrm{PC}_{71} \mathrm{BM}$ blends on the nanosecond time scale. We found no apparent difference in the charge dynamics between the PDI and $\mathrm{PC}_{71} \mathrm{BM}$ blends, indicating that there is no intrinsic disadvantage for NFAs in terms of charge generation, i.e. fullerenes are not so "special". Figure 5b shows the excitation wavelength dependence of charge dynamics in the PDI blend. As clearly seen in the figure, the charge dynamics are independent of the excitation wavelength, indicating that both electron transfer from PTB7-Th to bay-di-PDI (excited at $650 \mathrm{~nm}$ ) and hole transfer from bay-di-PDI to PTB7-Th result in efficient charge generation. This is consistent with the EQE spectra for this blend which follows the absorption spectra. It is interesting to investigate the separate roles of electrons and holes in the charge dissociation process. We do find that the charge dissociation process is strongly dependent on the morphology of both donor and acceptor, indicating that both the donor and acceptor do play an important role in the charge dissociation process. 
$<<<$ Figure 5 $>>>$

\section{Efficient charge separation with small driving force}

We have demonstrated the first efficient charge generation with small photon energy loss [28]. We used a high-efficient donor polymer, PNTz4T or PNOz4T, blended with $\mathrm{PC}_{71} \mathrm{BM}$. The PNTz4T-based device had an $E_{\mathrm{g}}$ of $1.56 \mathrm{eV}$ (based on absorption onset) and showed a PCE of $10.1 \%$ with a high short-circuit current density ( $\left.J_{\mathrm{SC}}\right)$ of $19.4 \mathrm{~mA}$ $\mathrm{cm}^{-2}$ [55]. However, the $E_{\text {loss }}$ was as large as $0.85 \mathrm{eV}$, resulting in a $V_{\mathrm{OC}}$ of only $0.71 \mathrm{~V}$. Such a large $E_{\text {loss }}$ is partly because of a large LUMO energy offset between PNTz4T and $\mathrm{PC}_{71} \mathrm{BM}$. In contrast, the PNOz4T-based device showed an $E_{\mathrm{g}}$ of $1.52 \mathrm{eV}$ [56], which is almost the same as the PNTz4T-based device, and a $V_{\text {OC }}$ of $0.96 \mathrm{~V}$, resulting in an $E_{\text {loss }}$ of $0.56 \mathrm{eV}$ [28]. Surprisingly, the $J_{\mathrm{SC}}$ and PCE were as high as $14.6 \mathrm{~mA} \mathrm{~cm}{ }^{-2}$ and $8.9 \%$, respectively. This results in our system having the highest known PCE among OSCs with an $E_{\text {loss }}$ less than $0.6 \mathrm{eV}$ (at least in 2015).

We expected that the origin of the small $E_{\text {loss }}$ in the PNOz4T-based device is a small LUMO energy offset. To confirm this, we measured the temperature dependence of the $V_{\mathrm{OC}}$ as shown in Figure 6 . The $V_{\mathrm{OC}}$ increased linearly with decreasing temperature. It is 
well known that the effective bandgap $\left(E_{\mathrm{g}}{ }^{\text {eff }}\right)$ obtained from the intersection at $0 \mathrm{~K}$ is a good indicator for $E_{\mathrm{CT}}$ because the $E_{\mathrm{g}}{ }^{\text {eff }}$ is identical with the $E_{\mathrm{CT}}$ at $0 \mathrm{~K}[57,58]$. Note that the $E_{\mathrm{CT}}$ at room temperature is typically $0.1-0.2 \mathrm{eV}$ above the $E_{\mathrm{g}}{ }^{\text {eff }}$. The $E_{\mathrm{g}}{ }^{\text {eff }}$ for the PNOz4T- and PNTz4T-based devices were 1.38 and $1.07 \mathrm{eV}$, respectively. Thus, the difference between the $E_{\mathrm{g}}$ and $E_{\mathrm{CT}}$ in the PNOz4T-based device at room temperature would be less than $0.14 \mathrm{eV}$, whilst it is as large as $0.4-0.5 \mathrm{eV}$ in the PNTz4T-based device. This is consistent with the observation that the electroluminescence (EL) spectrum of the PNOz4T/PC ${ }_{71} \mathrm{BM}$ device is almost the same as that of the PNOz4T pristine device. This indicates that charge generation in the PNOz4T-based device is efficient even though the LUMO energy offset is smaller than the empirical threshold of $0.3 \mathrm{eV}$.

$$
<<<\text { Figure 6>>> }
$$

Figure 7a,b shows the TA spectra for the $\mathrm{PNTz} 4 \mathrm{~T} / \mathrm{PC}_{71} \mathrm{BM}$ and $\mathrm{PNOz} 4 \mathrm{~T} / \mathrm{PC}_{71} \mathrm{BM}$ blend films. Immediately after photoexcitation, PIA bands attributable to singlet excitons were observed at 1100-1400 $\mathrm{nm}$ in both blends. In the PNTz4T blend, singlet excitons had almost disappeared within 10 ps, which is a sign of fine morphology. Instead, another PIA band ascribable to PNTz4T polarons was observed centred at $1100 \mathrm{~nm}$, which then 
slightly decayed on the nanosecond time scale through geminate recombination, probably as a result of the well-mixed disordered morphology. In contrast, singlet excitons decayed slowly in the PNOz4T blend, which implies large phase-separated domains or slow CT at the interface. Interestingly, a contribution from polaron absorption was observed for the TA data even at 0 ps, which indicates immediate CT of some excitons that generated very close to the interface. This suggests that CT itself is still fast and efficient even in the PNOz4T blend, and hence the slow exciton decay kinetics is attributable to a large domain size. This is consistent with the difference in morphology of the two blends observed in the transmission electron micrography images. What is important in our findings is that no polaron decay was observed in the PNOz4T blend up to 3 ns, which is clear evidence of efficient charge dissociation. We therefore conclude that, in the PNOz4T-based device, excitons dissociate into charges very efficiently without a large driving force. Although the mechanism of efficient charge dissociation without a large offset is still unclear, probably the highly crystalline nature of PNOz4T is essential for the charge dissociation, and this study clearly demonstrates the potential advantages of utilising small offset systems. 


\section{Conclusion}

This focus review highlights our recent studies using TA spectroscopy to investigate charge generation and recombination dynamics in OSCs. The impacts of polymer crystallinity on charge dissociation efficiency, mechanisms of charge dissociation in NFA-based OSCs, and efficient charge dissociation with a small LUMO energy offset were described. It was shown that the crystallisation or aggregation of materials promotes charge dissociation, which is rationalised by the delocalisation of charge wave functions in the crystalline or aggregate domains. State-of-the-art OSCs consist of wide-bandgap donor polymers and low-bandgap NFAs with a small HOMO energy offset, but understanding charge generation mechanisms with a small energy offset remains a challenge. Further spectroscopic studies will provide comprehensive understanding and clear design concepts for materials and devices.

\section{Author Information}

\section{ORCID}

Yasunari Tamai: 0000-0002-3074-0208 


\section{Notes}

The authors declare no competing financial interest.

\section{Acknowledgements}

The author thanks Prof Sir Richard Friend, Dr S. Matthew Menke, Prof Itaru Osaka, Prof Shinzaburo Ito and Prof Hideo Ohkita for their fruitful discussion. The author also thanks all other collaborators. This work was partly supported by JSPS Postdoctoral Fellowships for Research Abroad, JSPS KAKENHI Grant-in-Aid for Young Scientists (B) No. 17K14527, and JST PRESTO program Grant Number JPMJPR1874. The author also acknowledges financial supports from Trycom Advance Co., Ltd.

\section{References}

1. Clarke TM., Durrant JR. Charge photogeneration in organic solar cells. Chem Rev. 2010; 110: 6736-67.

2. $\quad$ Lu L., Zheng T., Wu Q., Schneider AM., Zhao D., Yu L. Recent advances in bulk heterojunction polymer solar cells. Chem Rev. 2015; 115: 12666-731.

3. Inganas O. Organic photovoltaics over three decades. Adv Mater. 2018; 30: 1800388.

4. Hou J., Inganas O., Friend RH., Gao F. Organic solar cells based on non-fullerene acceptors. Nat Mater. 2018; 17: 119-28. 
5. Guo JM., Ohkita H., Benten H., Ito S. Charge generation and recombination dynamics in poly(3-hexylthiophene)/fullerene blend films with different regioregularities and morphologies. J Am Chem Soc. 2010; 132: 6154-64.

6. Halls JJM., Walsh CA., Greenham NC., Marseglia EA., Friend RH., Moratti SC., Holmes AB. Efficient photodiodes from interpenetrating polymer networks. Nature. 1995; 376: 498-500.

7. Zhan C., Zhang X., Yao J. New advances in non-fullerene acceptor based organic solar cells. RSC Adv. 2015; 5: 93002-26.

8. McAfee SM., Topple JM., Hill IG., Welch GC. Key components to the recent performance increases of solution processed non-fullerene small molecule acceptors. J Mater Chem A. 2015; 3: 16393-408.

9. McNeill CR., Westenhoff S., Groves C., Friend RH., Greenham NC. Influence of nanoscale phase separation on the charge generation dynamics and photovoltaic performance of conjugated polymer blends: Balancing charge generation and separation. J Phys Chem C. 2007; 111: 19153-60.

10. Westenhoff S., Howard IA., Hodgkiss JM., Kirov KR., Bronstein HA., Williams CK., Greenham NC., Friend RH. Charge recombination in organic photovoltaic devices with high open-circuit voltages. J Am Chem Soc. 2008; 130: 13653-8.

11. Hodgkiss JM., Campbell AR., Marsh RA., Rao A., Albert-Seifried S., Friend RH. Subnanosecond geminate charge recombination in polymer-polymer photovoltaic devices. Phys Rev Lett. 2010; 104: 177701.

12. Moore JR., Albert-Seifried S., Rao A., Massip S., Watts B., Morgan DJ., Friend RH., McNeill CR., Sirringhaus H. Polymer blend solar cells based on a highmobility naphthalenediimide-based polymer acceptor: Device physics, photophysics and morphology. Adv Energy Mater. 2011; 1: 230-40.

13. Schubert M., Collins BA., Mangold H., Howard IA., Schindler W., Vandewal K., Roland S., Behrends J., Kraffert F., Steyrleuthner R., Chen Z., Fostiropoulos K., Bittl R., Salleo A., Facchetti A., Laquai F., Ade HW., Neher D. Correlated 
donor/acceptor crystal orientation controls photocurrent generation in all-polymer solar cells. Adv Funct Mater. 2014; 24: 4068-81.

14. Gehrig DW., Roland S., Howard IA., Kamm V., Mangold H., Neher D., Laquai F. Efficiency-limiting processes in low-bandgap polymer:perylene diimide photovoltaic blends. J Phys Chem C. 2014; 118: 20077-85.

15. Zhang GY., Zhao JB., Chow PCY., Jiang K., Zhang JQ., Zhu ZL., Zhang J., Huang F., Yan H. Nonfullerene acceptor molecules for bulk heterojunction organic solar cells. Chem Rev. 2018; 118: 3447-507.

16. Wadsworth A., Moser M., Marks A., Little MS., Gasparini N., Brabec CJ., Baran D., McCulloch I. Critical review of the molecular design progress in non-fullerene electron acceptors towards commercially viable organic solar cells. Chem Soc Rev. 2019; 48: 1596-625.

17. Yuan J., Zhang YQ., Zhou LY., Zhang GC., Yip HL., Lau TK., Lu XH., Zhu C., Peng HJ., Johnson PA., Leclerc M., Cao Y., Ulanski J., Li YF., Zou YP. Singlejunction organic solar cell with over 15\% efficiency using fused-ring acceptor with electron-deficient core. Joule. 2019; 3: 1140-51.

18. Lin YB., Adilbekova B., Firdaus Y., Yengel E., Faber H., Sajjad M., Zheng XP., Yarali E., Seitkhan A., Bakr OM., El-Labban A., Schwingenschlogl U., Tung V., McCulloch I., Laquai F., Anthopoulos TD. 17\% efficient organic solar cells based on liquid exfoliated $\mathrm{WS}_{2}$ as a replacement for PEDOT:PSS. Adv Mater. 2019; 31: 9.

19. Cui Y., Yao HF., Zhang JQ., Zhang T., Wang YM., Hong L., Xian KH., Xu BW., Zhang SQ., Peng J., Wei ZX., Gao F., Hou JH. Over 16\% efficiency organic photovoltaic cells enabled by a chlorinated acceptor with increased open-circuit voltages. Nat Commun. 2019; 10: 8.

20. Menke SM., Ran NA., Bazan GC., Friend RH. Understanding energy loss in organic solar cells: Toward a new efficiency regime. Joule. 2018; 2: 25-35.

21. Li WW., Hendriks KH., Furlan A., Wienk MM., Janssen RAJ. High quantum 
efficiencies in polymer solar cells at energy losses below 0.6 eV. J Am Chem Soc. 2015; 137: 2231-4.

22. Tamai Y., Ohkita H., Shimada J., Benten H., Ito S., Yamanaka S., Hisada K., Tani K., Kubono K., Shinmyozu T. Dynamical excimer formation in rigid carbazolophane via charge transfer state. J Phys Chem A. 2013; 117: 7776-85.

23. Tamai Y., Ohkita H., Benten H., Ito S. Singlet fission in poly(9,9'-di- $n$ octylfluorene) films. J Phys Chem C. 2013; 117: 10277-84.

24. Tamai Y., Tsuda K., Ohkita H., Benten H., Ito S. Charge-carrier generation in organic solar cells using crystalline donor polymers. Phys Chem Chem Phys. 2014; 16: 20338-46.

25. Tamai Y., Ohkita H., Benten H., Ito S. Triplet exciton dynamics in fluorene-amine copolymer films. Chem Mater. 2014; 26: 2733-42.

26. Tamai Y., Matsuura Y., Ohkita H., Benten H., Ito S. One-dimensional singlet exciton diffusion in poly(3-hexylthiophene) crystalline domains. J Phys Chem Lett. 2014; 5: 399-403.

27. Tamai Y., Ohkita H., Benten H., Ito S. Exciton diffusion in conjugated polymers: From fundamental understanding to improvement in photovoltaic conversion efficiency. J Phys Chem Lett. 2015; 6: 3417-28.

28. Kawashima K., Tamai Y., Ohkita H., Osaka I., Takimiya K. High-efficiency polymer solar cells with small photon energy loss. Nat Commun. 2015; 6: 10085.

29. Kasai Y., Tamai Y., Ohkita H., Benten H., Ito S. Ultrafast singlet fission in a pushpull low-bandgap polymer film. J Am Chem Soc. 2015; 137: 15980-3.

30. Tamai Y., Ohkita H., Namatame M., Marumoto K., Shimomura S., Yamanari T., Ito S. Light-induced degradation mechanism in poly(3-hexylthiophene)/fullerene blend solar cells. Adv Energy Mater. 2016; 6.

31. Tamai Y., Fan Y., Kim VO., Ziabrev K., Rao A., Barlow S., Marder SR., Friend 
RH., Menke SM. Ultrafast long-range charge separation in nonfullerene organic solar cells. ACS Nano. 2017; 11: 12473-81.

32. Mauer R., Howard IA., Laquai F. Effect of nongeminate recombination on fill factor in polythiophene/methanofullerene organic solar cells. J Phys Chem Lett. 2010; 1: 3500-5.

33. Howard IA., Mauer R., Meister M., Laquai F. Effect of morphology on ultrafast free carrier generation in polythiophene:fullerene organic solar cells. J Am Chem Soc. 2010; 132: 14866-76.

34. Shoaee S., Subramaniyan S., Xin H., Keiderling C., Tuladhar PS., Jamieson F., Jenekhe SA., Durrant JR. Charge photogeneration for a series of thiazolo-thiazole donor polymers blended with the fullerene electron acceptors PCBM and ICBA. Adv Funct Mater. 2013; 23: 3286-98.

35. Gélinas S., Rao A., Kumar A., Smith SL., Chin AW., Clark J., van der Poll TS., Bazan GC., Friend RH. Ultrafast long-range charge separation in organic semiconductor photovoltaic diodes. Science. 2014; 343: 512-6.

36. Dimitrov SD., Durrant JR. Materials design considerations for charge generation in organic solar cells. Chem Mater. 2014; 26: 616-30.

37. Etzold F., Howard IA., Forler N., Cho DM., Meister M., Mangold H., Shu J., Hansen MR., Mullen K., Laquai F. The effect of solvent additives on morphology and excited-state dynamics in PCPDTBT:PCBM photovoltaic blends. J Am Chem Soc. 2012; 134: 10569-83.

38. Motaung DE., Malgas GF., Arendse CJ. Correlation between the morphology and photo-physical properties of P3HT:Fullerene blends. J Mater Sci. 2010; 45: 327683.

39. Salleo A., Kline RJ., DeLongchamp DM., Chabinyc ML. Microstructural characterization and charge transport in thin films of conjugated polymers. Adv Mater. 2010; 22: 3812-38. 
40. Chen H-Y., Hou J., Hayden AE., Yang H., Houk KN., Yang Y. Silicon atom substitution enhances interchain packing in a thiophene-based polymer system. Adv Mater. 2010; 22: 371-5.

41. Chen D., Nakahara A., Wei D., Nordlund D., Russell TP. P3HT/PCBM bulk heterojunction organic photovoltaics: Correlating efficiency and morphology. Nano Lett. 2011; 11: 561-7.

42. Agostinelli T., Ferenczi TAM., Pires E., Foster S., Maurano A., Müller C., Ballantyne A., Hampton M., Lilliu S., Campoy-Quiles M., Azimi H., Morana M., Bradley DDC., Durrant J., Macdonald JE., Stingelin N., Nelson J. The role of alkane dithiols in controlling polymer crystallization in small band gap polymer:fullerene solar cells. J Polym Sci B Polym Phys. 2011; 49: 717-24.

43. Yamamoto S., Ohkita H., Benten H., Ito S. Role of interfacial charge transfer state in charge generation and recombination in low-bandgap polymer solar cell. J Phys Chem C. 2012; 116: 14804-10.

44. Guilbert AAY., Frost JM., Agostinelli T., Pires E., Lilliu S., Macdonald JE., Nelson J. Influence of bridging atom and side chains on the structure and crystallinity of cyclopentadithiophene-benzothiadiazole polymers. Chem Mater. 2014; 26: 1226-33.

45. Mayer AC., Toney MF., Scully SR., Rivnay J., Brabec CJ., Scharber M., Koppe M., Heeney M., McCulloch I., McGehee MD. Bimolecular crystals of fullerenes in conjugated polymers and the implications of molecular mixing for solar cells. Adv Funct Mater. 2009; 19: 1173-9.

46. Cates NC., Gysel R., Beiley Z., Miller CE., Toney MF., Heeney M., McCulloch I., McGehee MD. Tuning the properties of polymer bulk heterojunction solar cells by adjusting fullerene size to control intercalation. Nano Lett. 2009; 9: 4153-7.

47. Hammond MR., Kline RJ., Herzing AA., Richter LJ., Germack DS., Ro H-W., Soles CL., Fischer DA., Xu T., Yu L., Toney MF., DeLongchamp DM. Molecular order in high-efficiency polymer/fullerene bulk heterojunction solar cells. ACS Nano. 2011; 5: 8248-57. 
48. Liu F., Gu Y., Jung JW., Jo WH., Russell TP. On the morphology of polymer-based photovoltaics. J Polym Sci B Polym Phys. 2012; 50: 1018-44.

49. Sweetnam S., Graham KR., Ndjawa GON., Heumueller T., Bartelt JA., Burke TM., Li W., You W., Amassian A., McGehee MD. Characterization of the polymer energy landscape in polymer:fullerene bulk heterojunctions with pure and mixed phases. J Am Chem Soc. 2014; 136: 14078-88.

50. Jamieson FC., Agostinelli T., Azimi H., Nelson J., Durrant JR. Field-independent charge photogeneration in PCPDTBT/PC ${ }_{70} \mathrm{BM}$ solar cells. J Phys Chem Lett. 2010; 1: 3306-10.

51. Shivanna R., Shoaee S., Dimitrov S., Kandappa SK., Rajaram S., Durrant JR., Narayan KS. Charge generation and transport in efficient organic bulk heterojunction solar cells with a perylene acceptor. Energy Environ Sci. 2014; 7: 435-41.

52. Rao A., Chow PC., Gelinas S., Schlenker CW., Li CZ., Yip HL., Jen AK., Ginger DS., Friend RH. The role of spin in the kinetic control of recombination in organic photovoltaics. Nature. 2013; 500: 435-9.

53. Chow PC., Gelinas S., Rao A., Friend RH. Quantitative bimolecular recombination in organic photovoltaics through triplet exciton formation. J Am Chem Soc. 2014; 136: 3424-9.

54. Gehrig DW., Howard IA., Laquai F. Charge carrier generation followed by triplet state formation, annihilation, and carrier recreation in PBDTTT-C/PC $60 \mathrm{BM}$ photovoltaic blends. J Phys Chem C. 2015; 119: 13509-15.

55. Vohra V., Kawashima K., Kakara T., Koganezawa T., Osaka I., Takimiya K., Murata H. Efficient inverted polymer solar cells employing favourable molecular orientation. Nat Photonics. 2015; 9: 403-8.

56. Kawashima K., Osaka I., Takimiya K. Effect of chalcogen atom on the properties of naphthobischalcogenadiazole-based $\pi$-conjugated polymers. Chem Mater. 
2015; 27: 6558-70.

57. Vandewal K., Tvingstedt K., Manca JV., Inganäs O. Charge-transfer states and upper limit of the open-circuit voltage in polymer:fullerene organic solar cells. IEEE J Sel Top Quantum Electron. 2010; 16: 1676-84.

58. Vandewal K., Tvingstedt K., Gadisa A., Inganäs O., Manca JV. Relating the opencircuit voltage to interface molecular properties of donor:acceptor bulk heterojunction solar cells. Phys Rev B. 2010; 81. 


\section{Titles and Legends to Figures}

Figure 1. (a) Photocurrent conversion processes in OSCs: (1) photon absorption to generate singlet excitons, (2) exciton diffusion to the DA interface, (3) charge transfer to generate CT excitons, (4) dissociation of CT excitons into free carriers, and (5) charge collection to each electrode. (b) Exciton diffusion followed by charge transfer at the interface. (c) Geminate recombination and charge dissociation of CT excitons.

Figure 2. (a) TA spectra of the PSBTBT/PCBM blend film excited at $800 \mathrm{~nm}$ with a fluence of $11 \mu \mathrm{J} \mathrm{cm}^{-2}$. The broken line represents the PIA band of PSBTBT singlet excitons observed for a PSBTBT pristine film. (b) Time evolution of polarons in the disordered phase (open triangles), and polarons in the crystalline phase (open squares) in the PSBTBT/PCBM blend film. The closed circles represent the total polaron density. Adapted from ref. [24] by permission of the PCCP Owner Societies.

Figure 3. TA spectra of the (a) PTB7-Th/bay-di-PDI blend, and (b) PTB7-Th/PC ${ }_{71} \mathrm{BM}$ blend, excited at $650 \mathrm{~nm}$ with a fluence of $1.6 \mu \mathrm{J} \mathrm{cm}^{-2}$. The spectra in the near-IR region (850-1050 nm) were rescaled to that of the IR region (1050-1400 nm) owing to a small change in the pump-probe overlap. Reprinted with permission from ref. [31]. Copyright 
2017 American Chemical Society.

Figure 4. (a,b) Normalised TA spectra in the visible region. Broken lines represent the TA spectra of the pristine PTB7-Th film as a reference. (c) Time evolution of the EA amplitude per unit charge obtained by dividing the EA amplitude by the charge signal. The right axis shows total electrostatic energy stored in the field per electron-hole pair. The energy is obtained assuming that half of the field is in the donor phase as $\frac{1}{2} \varepsilon_{0} \varepsilon_{\mathrm{r}} \int|E|^{2} d V$ and a taking a value of 3 for $\varepsilon_{\mathrm{r}}$. The spatially integrated square of the electric field was converted from the diode-based EA amplitude. Reprinted with permission from ref. [31]. Copyright 2017 American Chemical Society.

Figure 5. (a) Normalised time evolution of the polaron band in the PDI (red) and PC $71 \mathrm{BM}$ (black) blends. (b) Excitation wavelength dependence of polaron dynamics in the PDI blend. Reprinted with permission from ref. [31]. Copyright 2017 American Chemical Society.

Figure 6. Temperature dependence of the $V_{\mathrm{OC}}$ for the PNOz4T and PNTz4T-based devices. Adapted from ref. [28]. Copyright 2015 Springer Nature. 
Figure 7. (a,b) TA spectra of the PNTz4T/PC ${ }_{71} \mathrm{BM}$ and $\mathrm{PNOz} 4 \mathrm{~T} / \mathrm{PC}_{71} \mathrm{BM}$ blend films. (c,d) Normalised time evolution of the singlet excitons (blue) and polaron (red) bands in the PNTz4T/PC $71 \mathrm{BM}$ and $\mathrm{PNOz} 4 \mathrm{~T} / \mathrm{PC}_{71} \mathrm{BM}$ blend films. Green squares represent total density of singlet excitons and polarons. Adapted from ref. [28]. Copyright 2015 Springer Nature.

Table 1. Photovoltaic conversion efficiency of OSCs. 


\section{Display Items}

Figure 1
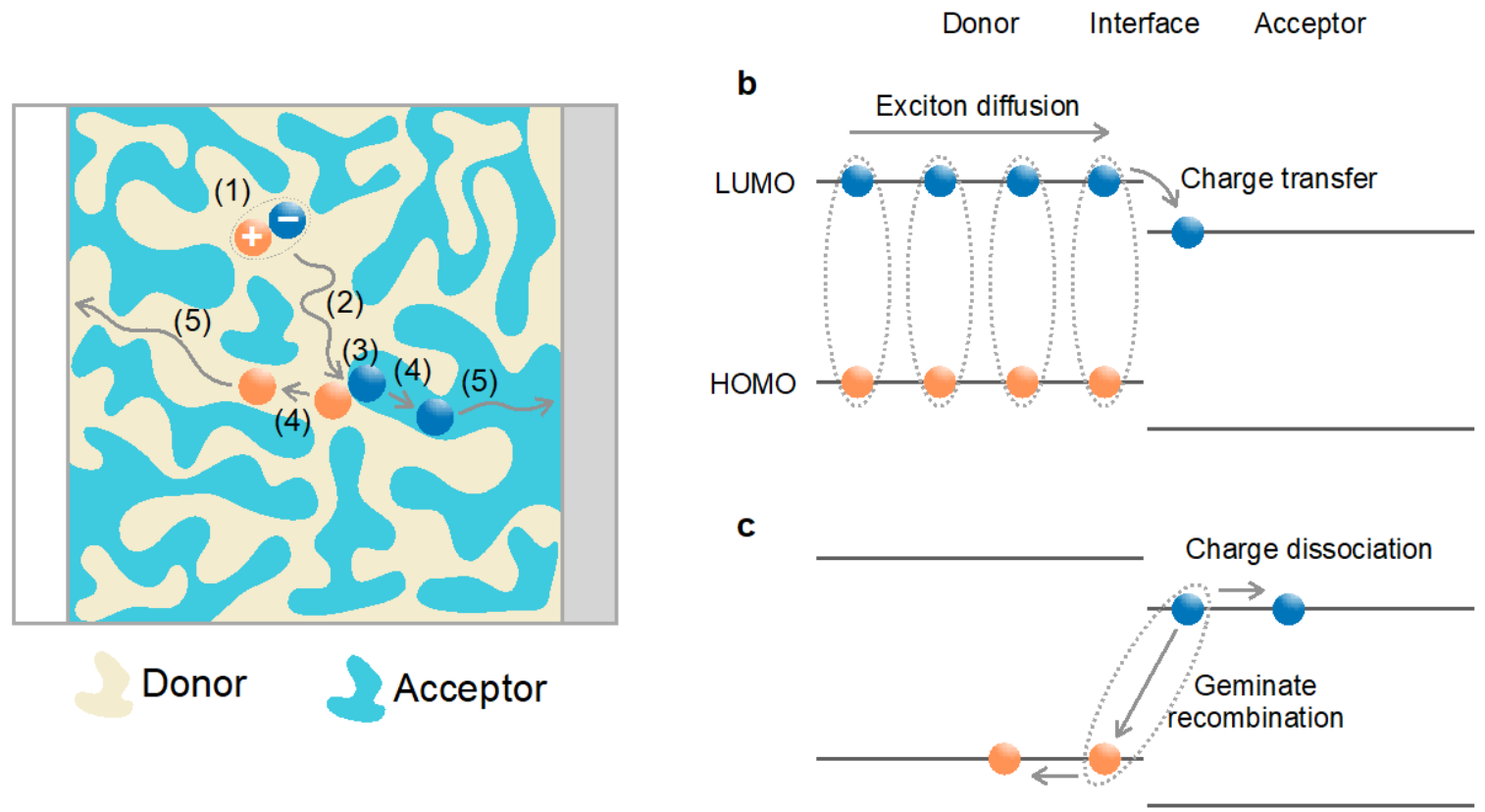
Figure 2
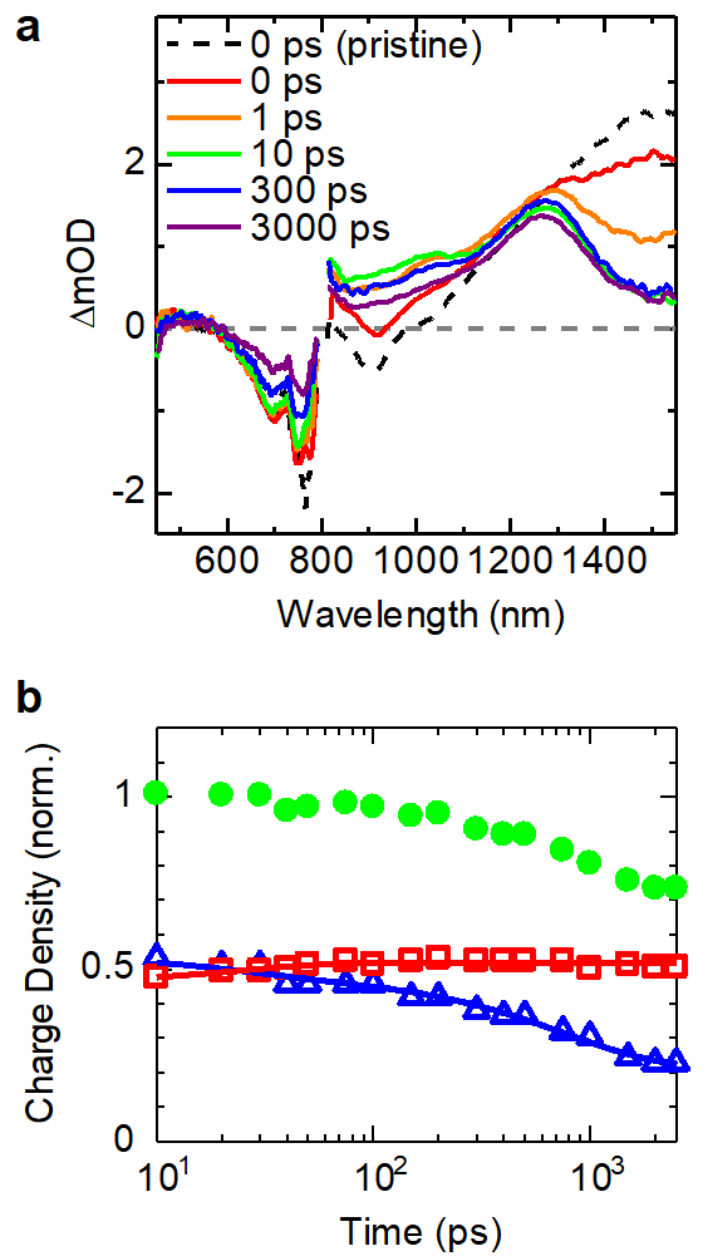
Figure 3
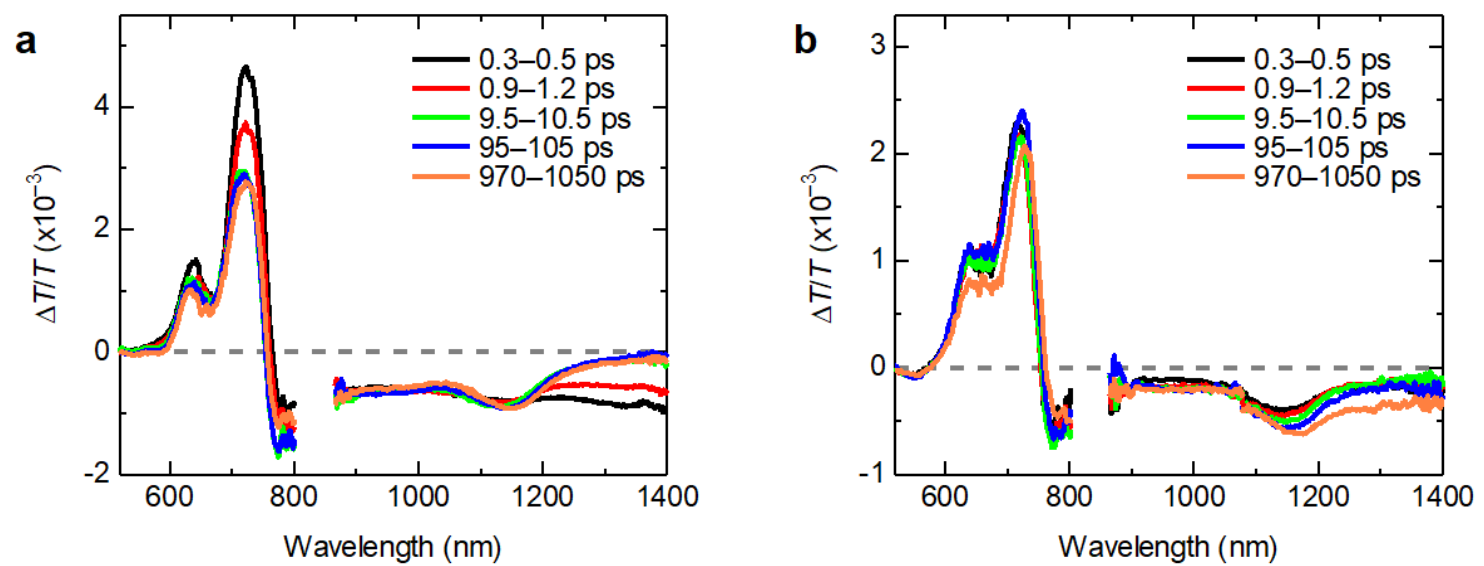
Figure 4

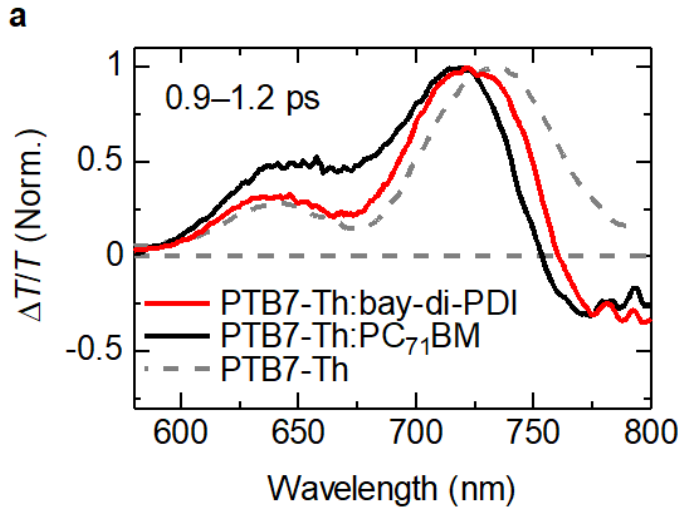

b
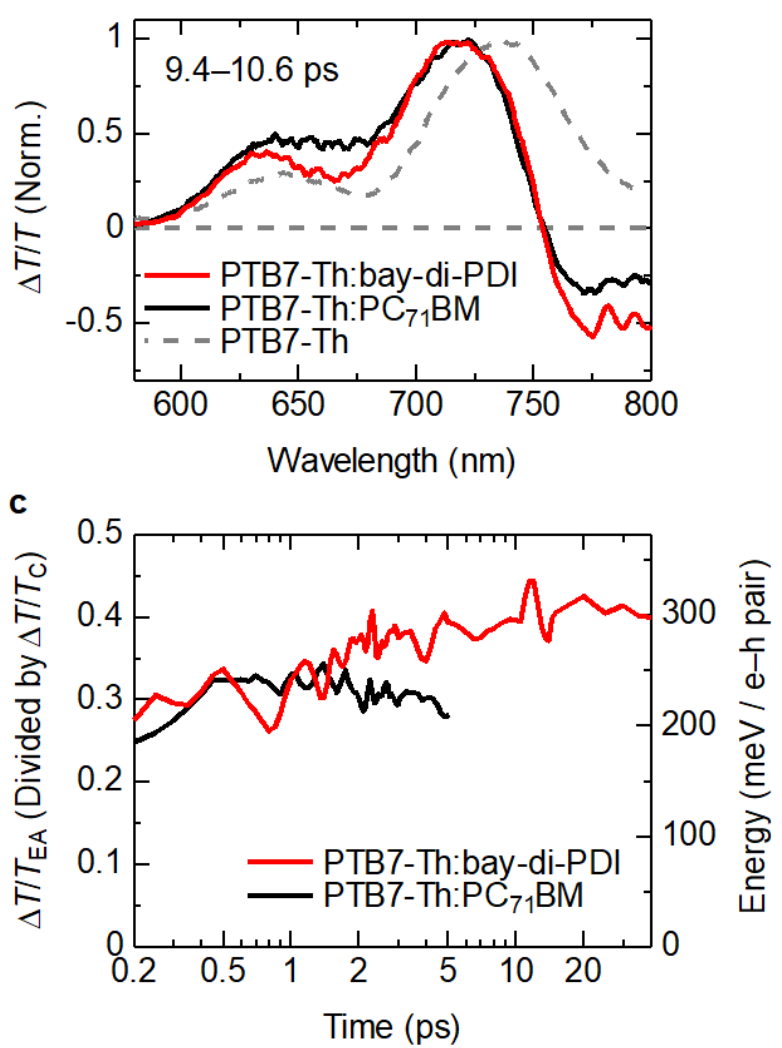
Figure 5

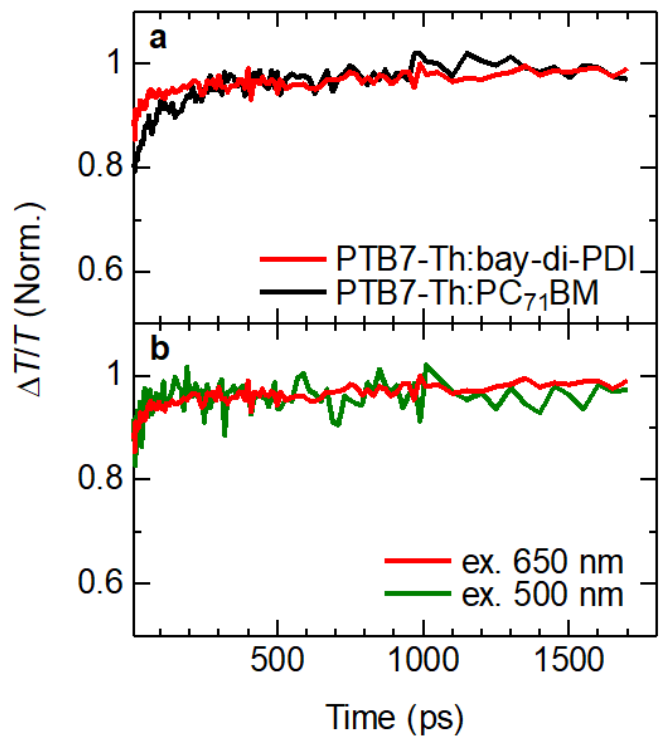


Figure 6

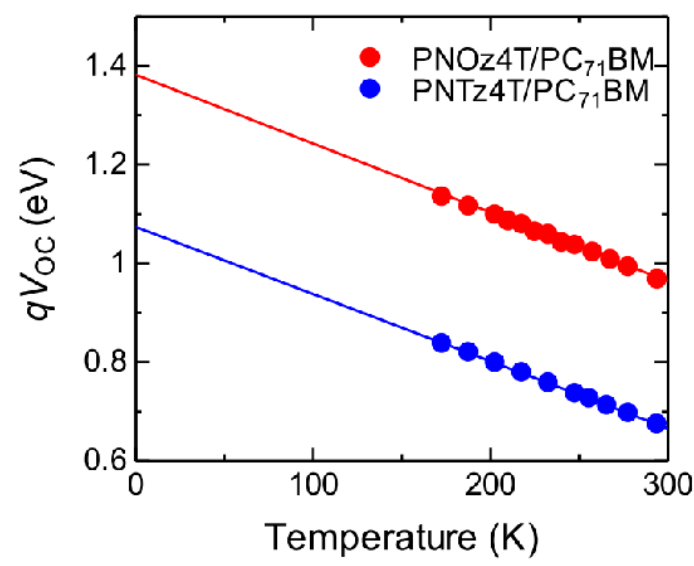


Figure 7

a
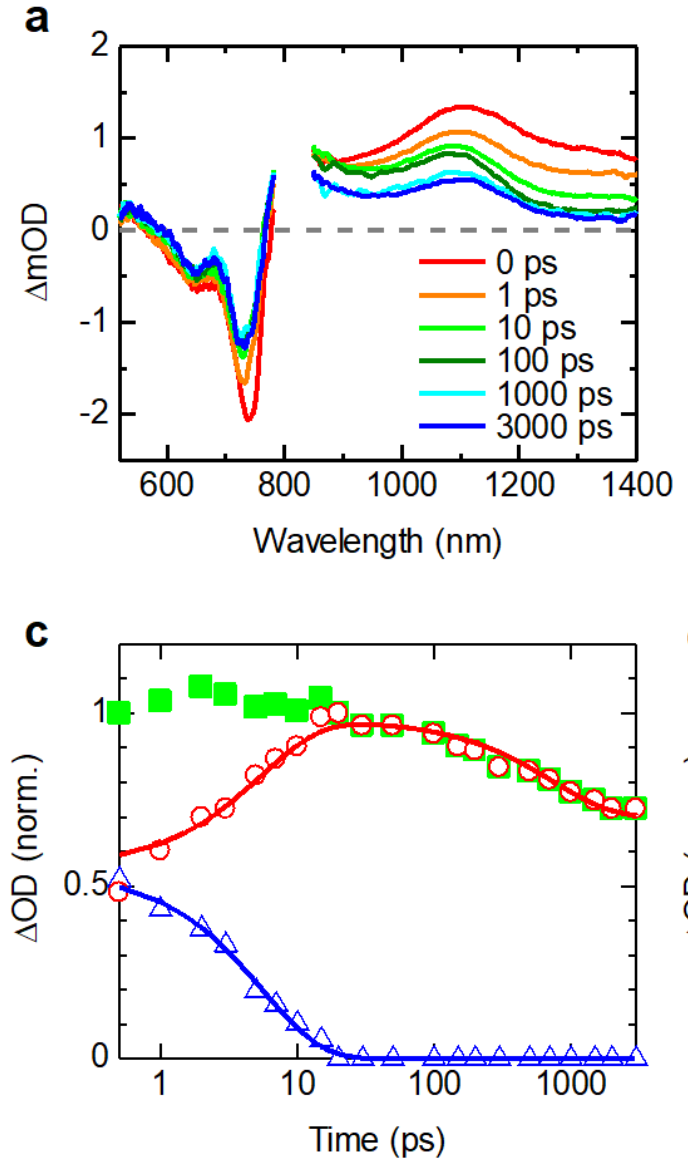
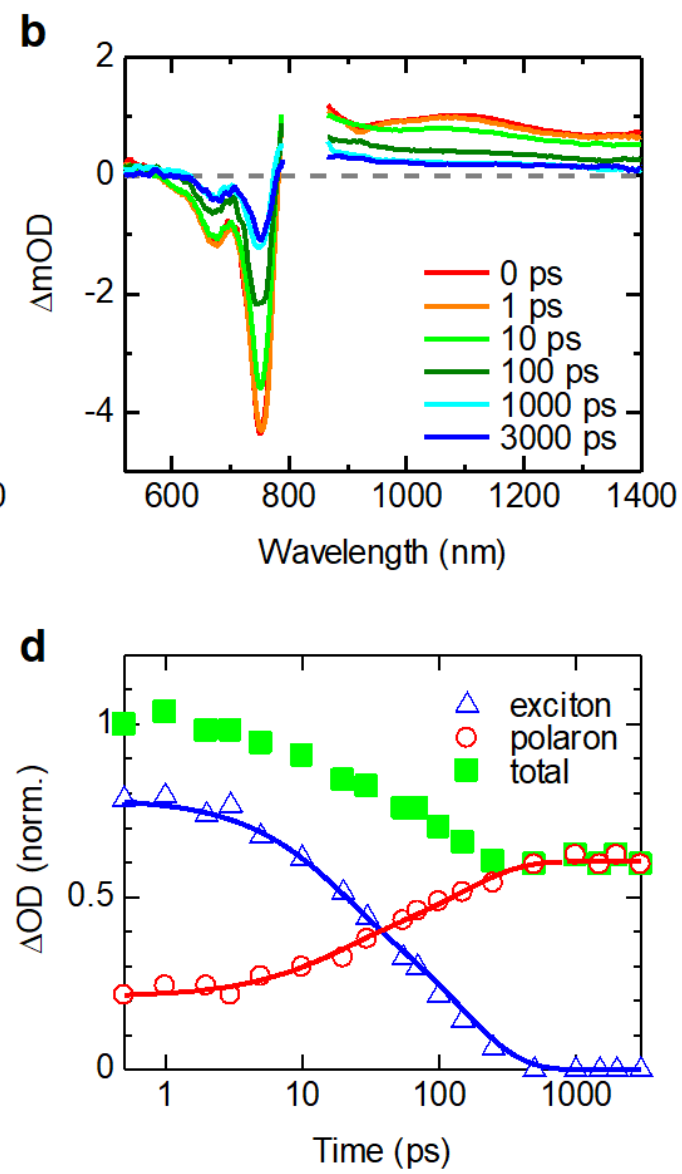


\section{Table 1}

\begin{tabular}{|c|c|c|c|c|c|c|}
\hline Polymers & phase & $\eta_{\mathrm{CD}}{ }^{\mathrm{cry}}$ & $\eta_{\mathrm{CD}}{ }^{\mathrm{dis}, a}$ & $\eta_{\mathrm{CD}}{ }^{\text {total }}$ & $L_{010}(\mathrm{~nm})^{b}$ & $d(\AA)^{b}$ \\
\hline $\begin{array}{l}\text { RR-P3HT } \\
\text { w anneal }\end{array}$ & $\begin{array}{c}\text { Highly } \\
\text { crystalline }\end{array}$ & $1^{[5]}$ & $(0.69)^{[5]}$ & $0.93^{[5]}$ & $\sim 12^{[41]}$ & $3.8^{[39]}$ \\
\hline $\begin{array}{l}\text { RR-P3HT } \\
\text { w/o anneal }\end{array}$ & $\begin{array}{c}\text { Modest } \\
\text { crystalline }\end{array}$ & $1^{[5]}$ & $(0.38)^{[5]}$ & $0.8^{[5]}$ & $\sim 5.7^{[38]}$ & $3.8^{[38]}$ \\
\hline PSBTBT & $\begin{array}{c}\text { Small } \\
\text { crystalline }\end{array}$ & $1^{[24]}$ & $0.51(0.12)^{[24]}$ & $0.75^{[24]}$ & $\sim 4.6^{[44]}$ & $3.5^{[40,44]}$ \\
\hline $\begin{array}{l}\text { PCPDTBT } \\
\text { w additives }\end{array}$ & $\begin{array}{l}\text { Slightly } \\
\text { ordered }\end{array}$ & - & - & $0.7^{[37,43]}$ & $(\sim 1.1)^{[42]}$ & $(3.8)^{[42]}$ \\
\hline $\begin{array}{c}\text { PCPDTBT } \\
\text { w/o additives }\end{array}$ & $\begin{array}{c}\text { Less } \\
\text { ordered }\end{array}$ & - & - & $0.5^{[37]}$ & $(\sim 0.5)^{[42]}$ & $(3.9)^{[42]}$ \\
\hline RRa-P3HT & Amorphous & - & $0.3^{[5]}$ & $0.3^{[5]}$ & - & - \\
\hline
\end{tabular}

$\eta_{\mathrm{CD}}{ }^{\text {cry }}, \eta_{\mathrm{CD}}{ }^{\text {dis }}$, and $\eta_{\mathrm{CD}^{\text {total }}}$ are charge dissociation efficiency in the crystalline phase, in the disordered phase, and overall, respectively.

${ }^{a}$ The value in parenthesis is the charge dissociation efficiency via the hole transfer.

${ }^{b}$ The value in parenthesis is obtained from PCPDTBT pristine films. No clear diffraction peaks have been reported for PCPDTBT in the blend films, suggesting that PCPDTBT forms less ordered aggregates in the blend films. 


\section{Graphical Abstract}

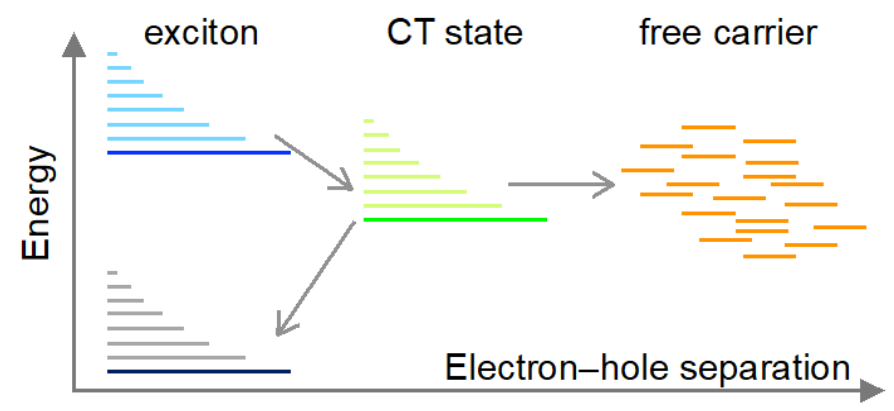

